\title{
A Generic, Scalable, and Rapid Time-Resolved Förster Resonance Energy Transfer-Based Assay for Antigen pÿDetection SARS-CoV-2 as a Proof of Concept
}

\section{Rusanen, Juuso}

2021-05-18

Rusanen , J , Kareinen , L , Szirovicza , L , Ugurlu , H , Levanov , L , Jääskeläinen , A , Ahava, M J , Kurkela , S , Saksela , K, Hedman, K, Vapalahti , O \& Hepojoki , J 2021 , ' A Generic, Scalable, and Rapid Time-Resolved Förster Resonance Energy Transfer-Based pÿAssay for Antigen Detection SARS-CoV-2 as a Proof of Concept ' , mBio , vol. 12 , no. 3 , e00902-21 . https://doi.org/10.1128/mBio.00902-21

http://hdl.handle.net/10138/339554

https://doi.org/10.1128/mBio.00902-21

cc_by

publishedVersion

Downloaded from Helda, University of Helsinki institutional repository.

This is an electronic reprint of the original article.

This reprint may differ from the original in pagination and typographic detail.

Please cite the original version. 


\title{
A Generic, Scalable, and Rapid Time-Resolved Förster Resonance Energy Transfer-Based Assay for Antigen Detection-SARS-CoV-2 as a Proof of Concept
}

\author{
(D) Juuso Rusanen,a (D) Lauri Kareinen, a,b (D) Leonora Szirovicza,a (D) Hasan Uğurlu, Lev Levanov,a (D) Anu Jääskeläinen, ${ }^{c, d}$ \\ Maarit Ahava, ${ }^{c, d}$ Satu Kurkela, c,d (D) Kalle Saksela, a (D) Klaus Hedman,, a,c,d Olli Vapalahti, a,b,c,d (D) Jussi Hepojokia,e \\ aUniversity of Helsinki, Faculty of Medicine, Medicum, Department of Virology, Helsinki, Finland \\ bUniversity of Helsinki, Faculty of Veterinary Medicine, Department of Veterinary Biosciences, Helsinki, Finland \\ cHUS Diagnostic Center, HUSLAB, Clinical Microbiology, University of Helsinki, Helsinki, Finland \\ dHelsinki University Hospital, Helsinki, Finland \\ eUniversity of Zürich, Vetsuisse Faculty, Institute of Veterinary Pathology, Zürich, Switzerland
}

ABSTRACT The ongoing coronavirus disease 2019 (COVID-19) pandemic has seen an unprecedented increase in the demand for rapid and reliable diagnostic tools, leaving many laboratories scrambling for resources. We present a fast and simple assay principle for antigen detection and demonstrate its functionality by detecting severe acute respiratory syndrome coronavirus 2 (SARS-CoV-2) antigens in nasopharyngeal swabs. The method is based on the detection of SARS-CoV-2 nucleoprotein (NP) and S protein (SP) via time-resolved Förster resonance energy transfer (TR-FRET) with donor- and acceptor-labeled polyclonal anti-NP and -SP antibodies. Using recombinant proteins and cell culture-grown SARS-CoV-2, the limits of detection were established as $25 \mathrm{pg}$ of NP or 20 infectious units (IU) and $875 \mathrm{pg}$ of SP or $625 \mathrm{IU}$. Testing reverse transcription-PCR (RT-PCR)-positive $(n=48$, with cycle threshold $\left[C_{T}\right]$ values from 11 to 30$)$ or -negative $(n=96)$ nasopharyngeal swabs demonstrated that the assay yielded positive results for all samples with $C_{T}$ values of $<25$ and for a single RT-PCR-negative sample. Virus isolation from the RT-PCR-positive nasopharyngeal swabs showed a strong association between the presence of infectious virus and a positive antigen test result. The NP-based assay showed $97.4 \%$ (37/38) sensitivity and $100 \%$ (10/10) specificity in comparison with virus isolation and $77.1 \%$ (37/48) sensitivity and 99.0\% (95/96) specificity in comparison with SARS-CoV-2 RT-PCR. The assay is performed in a buffer that neutralizes SARS-CoV-2 infectivity, and the assay is relatively simple to set up as an "in-house" test. Here, SARS-CoV-2 served as the model pathogen, but the assay principle is applicable to other viral infections, and the test format could easily be adapted to high-throughput testing.

IMPORTANCE PCR is currently the gold standard for the diagnosis of many acute infections. While PCR and its variants are highly sensitive and specific, the time from sampling to results is measured in hours at best. Antigen tests directly detect parts of the infectious agent, which may enable faster diagnosis but often at lower sensitivity and specificity. Here, we describe a technique for rapid antigen detection and demonstrate the test format's potential using SARS-CoV-2 as the model pathogen. The 10-min test, performed in a buffer that readily inactivates SARS-CoV-2, from nasopharyngeal samples identified $97.4 \%$ (37/38) of the samples from which we could isolate the virus. This suggests that the test performs well in identifying patients potentially shedding the virus. Although SARS-CoV-2 served as the model pathogen to demonstrate proof of concept, the test principle itself would be applicable to a wide variety of infectious and perhaps also noninfectious diseases.
Citation Rusanen J, Kareinen L, Szirovicza L, Uğurlu $\mathrm{H}$, Levanov L, Jääskeläinen $\mathrm{A}$, Ahava $\mathrm{M}$ Kurkela S, Saksela K, Hedman K, Vapalahti O, Hepojoki J. 2021. A generic, scalable, and rapid time-resolved Förster resonance energy transfer-based assay for antigen detectionSARS-CoV-2 as a proof of concept. mBio 12 : e00902-21. https://doi.org/10.1128/mBio .00902-21.

Editor Dimitrios Paraskevis, Medical School, National and Kapodistrian University of Athens Copyright $\odot 2021$ Rusanen et al. This is an open-access article distributed under the terms of the Creative Commons Attribution 4.0 International license. Address correspondence to Jussi Hepojoki, jussi.hepojoki@helsinki.fi.

Received 25 March 2021

Accepted 19 April 2021

Published 18 May 2021 
KEYWORDS antigen test, COVID-19, SARS-CoV-2, TR-FRET, mix and read, rapid diagnostic test

T he ongoing coronavirus disease 2019 (COVID-19) pandemic has by December 2020 claimed almost 1.5 million lives globally, with over 60 million confirmed infections. To manage the disease, accurate diagnostic tools are of key importance. Detection of the causative agent, severe acute respiratory syndrome coronavirus 2 (SARS-CoV-2), or its parts is the cornerstone of diagnosis, as the disease presentation is often indistinguishable from those of other respiratory infections. The mainstay of COVID-19 diagnosis is reverse transcription-PCR (RT-PCR) testing, done typically from a nasopharyngeal swab (NPS), while oropharyngeal or midturbinate swabs as well as salivary samples are also in use. Alternatively, the less-labor-intensive antigen detection tests are also increasingly being deployed. Antigen tests tend to be specific but analytically less sensitive than RT-PCR. RT-PCR can detect viral nucleic acid even after the infectious virus has waned, with the individual at this time being unlikely to pose a transmission risk (1-3). Evidence suggests that antigen testing may correlate with the recovery of infectious virus better than a binary RT-PCR (4). Frequent antigen testing has been proposed as an alternative approach in reducing the community transmission of SARSCoV-2 (5).

SARS-CoV-2 is an enveloped positive-sense single-stranded RNA [(+)ssRNA] virus of the genus Betacoronavirus subfamily Orthocoronavirinae in the family Coronaviridae of the order Nidovirales. It contains four structural proteins. The nucleoprotein (NP) forms a ribonucleoprotein complex with the $30-\mathrm{kb}$ nonsegmented viral genome. The envelope (E) and membrane (M) proteins are embedded in the envelope, as is the spike protein (SP), protruding from the virion surface and generating large surface projections termed the corona. The SP undergoes processing to yield S1, which contains the receptor-binding domain (RBD) initially attaching the virus to angiotensin-converting enzyme 2 (ACE-2) on the host cell membrane, and S2, which mediates virus-cell fusion. In response to the pandemic, dozens of commercial SARS-CoV-2 antigen tests are available, predominantly of a lateral flow or enzyme immunoassay type. Most target NP as the analyte (6). Of the seven antigen tests having received emergency use authorization (EUA) from the U.S. Food and Drug Administration (FDA) by December 2020, six target NP, and one targets SP (7).

Over the past few years, we have actively employed time-resolved Förster resonance energy transfer (TR-FRET) as the basis of rapid homogeneous "mix-and-read" immunoassays for antibody detection (8-14). FRET occurs when a donor and an acceptor fluorophore are in proximity, whereby the excited donor transfers energy to the acceptor, which then emits a photon at a distinct wavelength. The closer the donor and acceptor are, the more frequent the energy transfer is, with a 50\% efficiency typically being achieved at a distance of 15 to $60 \AA$. Chelated lanthanide donor-enabled TR-FRET allows measurement from autofluorescent biological samples.

Here, we describe a rapid TR-FRET-based method for antigen detection and use SARS-CoV-2 NP and SP as the model antigens. In the assay, polyclonal anti-NP and anti-RBD rabbit antibodies, each labeled with either a donor or an acceptor fluorophore, are combined at an equimolar ratio and mixed with the clinical sample. The antigen, if present, binds the labeled antibodies and brings the fluorophores into proximity. This results in a TR-FRET signal upon excitation, indicating the presence of the antigen. We initially demonstrate the limits of detection (LODs) for recombinant NP and SP as well as cell culture-grown SARS-CoV-2. We then evaluate the assay performance among 48 RT-PCR-positive and 96 negative clinical NPS samples and compare the antigen detection results to those of RT-PCR and virus cultivation.

\section{RESULTS}

Proof of concept for the homogeneous antigen detection assay. We hypothesized that homogeneous, i.e., in-solution, detection of antigens could be achieved 
Reaction components

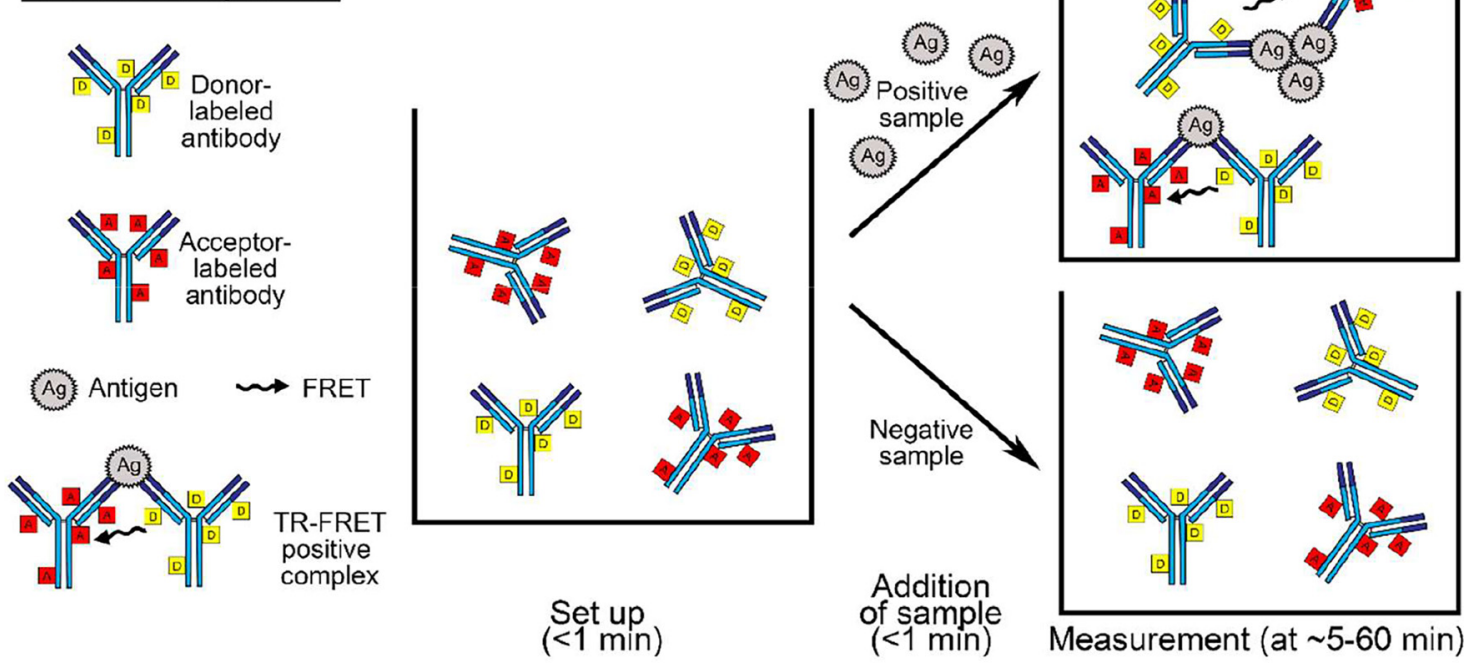

FIG 1 The TR-FRET assay workflow and principle. The left side shows the reaction components. At the center is a well containing donor- and acceptor-labeled antibodies at a 1:1 molar ratio in the reaction buffer; in our setup, the total antibody concentration at this point is $24 \mathrm{nM}$, and the volume is $10 \mu \mathrm{l}$. The arrows indicate the addition of the sample material, in our setup either $10 \mu \mathrm{l}$ of purified recombinant protein or $10 \mu \mathrm{l}$ of an NPS sample. The top right side shows schematically the antigen-antibody complexes formed following the addition of a sample containing the antigen; the reaction volume at this stage in our setup is $20 \mu \mathrm{l}$. The bottom right side schematically demonstrates that the labeled antibodies do not form TR-FRET active complexes in the absence of the antigen.

utilizing a polyclonal antibody separately labeled with fluorophores forming a FRET pair. To test the hypothesis and the assay principle presented in Fig. 1, we generated antisera against SARS-CoV-2 NP and the RBD of SP, with titers of $>204,800$ based on NP and SP enzyme-linked immunosorbent assays (ELISAs), respectively. Following affinity purification, the antibodies were labeled with chelated europium (Eu) (donor) and Alexa Fluor 647 (AF647) (acceptor). In the first experiments, we tested the assay principle by mixing recombinant NP and SP with $1 \mu \mathrm{M}(500 \mathrm{nM}$ Eu-labeled and $500 \mathrm{nM}$ AF647-labeled) anti-NP and anti-RBD antibody mixtures in the presence of increasing bovine serum albumin (BSA) concentrations. The addition of BSA increased the signalto-noise ratio, encouraging us to evaluate the assay performances further by utilizing infectious SARS-CoV-2-containing cell culture supernatants and different buffer compositions. The assay with $1 \mu \mathrm{M}$ antibody concentrations produced respectable signalto-noise ratios in detergent-containing RIPA (radioimmunoprecipitation assay) buffer (see Fig. S1 in the supplemental material). The RIPA buffer (see Materials and Methods for the full recipe) used here contained $1 \%$ NP-40 and $0.1 \%$ SDS, both of which have been shown to effectively inactivate the enveloped SARS-CoV-2 $(15,16)$, which is why we decided to employ RIPA buffer for the subsequent analyses.

Assay optimization using recombinant antigens and SARS-CoV-2. To optimize the assay performance, we mixed the labeled antibodies at equimolar ratios with known amounts of recombinant NP and SP and recorded the produced TR-FRET signals (as HTRF [homogeneous time-resolved fluorescence] values) as a function of time. The results showed that the assays produced the highest HTRF values when the concentration of labeled antibodies equaled the concentrations of the purified respective antigens (Fig. S2). Higher antibody concentrations shortened the time required to reach the signal peak (fold increase in the HTRF value, $\mathrm{HTRF}_{\text {sample }} / \mathrm{HTRF}_{\text {buffer }}$ ): with an antibody concentration of $5 \mathrm{nM}(2.5 \mathrm{nM}$ Eu- plus $2.5 \mathrm{nM}$ AF647-labeled antibodies), it took $\sim 60$ min for the signal to peak for both NP and SP, whereas with an antibody concentration of $500 \mathrm{nM}$, the NP signal peak occurred in $7 \mathrm{~min}$, and the SP signal peaked in $\sim 30 \mathrm{~min}$. We also tested the assay performances with Eu- and AF-labeled antibodies 
mixed at unequal proportions of $1: 2$ and 2:1, but this did not increase the signal-tobackground ratio (Table S1).

We then evaluated the assay performance at 50, 25, 12, and $6 \mathrm{nM}$ total antibody concentrations using SARS-CoV-2-containing cell culture supernatants at different dilutions. We included a UV-inactivated cell culture supernatant to find out whether UV inactivation would affect the analysis. The results concurred with the findings using recombinant antigens and showed the dependence of the TR-FRET signal kinetics on the antigen concentration (Fig. S3). The results further indicated that a $12 \mathrm{nM}$ total antibody concentration enables the measurement of antigens over a broad range of virus concentrations and that infectious and UV-inactivated SARS-CoV-2 produce similar results.

Limits of detection. To assess the limits of detection (LODs) for the assays at a $12 \mathrm{nM}$ total antibody concentration, we spiked a pool of NPS samples with either purified antigens or inactivated SARS-CoV-2 at different dilutions. With purified antigens, the lowest concentrations producing readily detectable signals were $0.05 \mathrm{nM}$ for NP and $0.5 \mathrm{nM}$ for SP (Fig. S4a and b). With UV-inactivated SARS-CoV-2, dilutions of the supernatant up to 1:5,120 and 1:160 produced reliably measurable signals with anti-NP and anti-RBD antibodies, respectively (Fig. S4c and d). With the 10- $\mu$ l sample volume, the detection limits of the assay were $\sim 25 \mathrm{pg}$ for recombinant NP (using a molecular weight of $50 \mathrm{kDa}$ ) and $875 \mathrm{pg}$ for SP (using a molecular weight of $175 \mathrm{kDa}$ ). Correspondingly, the NP assay could detect approximately 15 PFU and the RBD assay could detect approximately 420 PFU (converted by using the formula $0.7 \times 50 \%$ tissue culture infectious doses $\left[\mathrm{TCID}_{50}\right]$ per milliliter $=$ PFU per milliliter) per reaction.

Detection of SARS-CoV-2 antigens in NPS samples. After setting up the assay conditions using recombinant proteins and cell culture-grown virus, we tested the assays for the detection of viral antigen in SARS-CoV-2 RT-PCR-positive NPS samples. We had 48 NPS samples with RT-PCR cycle threshold $\left(C_{T}\right)$ values linearly ranging from $\sim 12$ to 30 (Fig. S5) and employed total antibody concentrations of 50, 25, 12, and $6 \mathrm{nM}$. We observed that samples with $C_{T}$ values of $\leq 25$ yielded a signal in the NP assay (Fig. S6). By using the optimized conditions with $12 \mathrm{nM}$ total labeled antibodies, the sensitivity of the NP TR-FRET assay in comparison with RT-PCR was 77.1\% (37/48). The SP assay showed greater diversity; most samples with $C_{T}$ values of $\leq 15$ yielded a positive result (Fig. S6). We also performed immunoblotting to detect NP and SP in NPS samples covering the $C_{T}$ value range of 12.8 to 26.2 and could detect SP and NP in samples with $C_{T}$ values of $<22$ (Fig. S7).

Association between infectious virus and antigen detection. To determine to what extent the antigen assays correspond to the amounts of infectious virus in the sample, we subjected the 48 SARS-CoV-2 RT-PCR-positive NPS samples to virus isolation. Transmembrane serine protease 2 (TMPRSS2) has been reported to function in priming SARS-CoV-2 spike for entry (17), and we thus chose to use both wild-type Vero E6 cells and a clonal population of TMPRSS2-expressing Vero E6 cells (VE6-TMPRSS2H10) (Fig. S8). As indicated by cytopathic effects (CPEs) as well as RT-PCR from the cell culture supernatants, SARS-CoV-2 was isolated from 35/48 and 38/48 NPS samples with Vero E6 and VE6-TMPRSS2-H10 cells, respectively. Interestingly, the cell culture supernatants from VE6-TMPRSS2-H10 cells yielded a positive result 3 to 5 cycles earlier than did the supernatants from Vero E6 cells, pointing to $\sim 10$ to 40 times more efficient virus production (Fig. S9). Altogether, infectious SARS-CoV-2 was recovered from all samples showing $C_{T}$ values of $\leq 24.5$. We then compared the antigen assay to virus isolation from the respective samples and observed that all of the samples with $C_{T}$ values of $\leq 24.5$ were positive in the NP assay (Fig. 2a). Of the samples with $C_{T}$ values of $>24.5$, all produced a negative result in the TR-FRET NP assay, and SARS-CoV-2 was recovered from only one sample $\left(C_{T}, 24.87\right)$. By using the optimized conditions with $12 \mathrm{nM}$ total labeled antibodies, the sensitivity of the NP assay in comparison with virus isolation was $97.4 \%$ (37/38). The performance of the SP assay was poorer; only 8/38 samples with recoverable SARS-CoV-2 yielded a positive result (Fig. 2 b). 

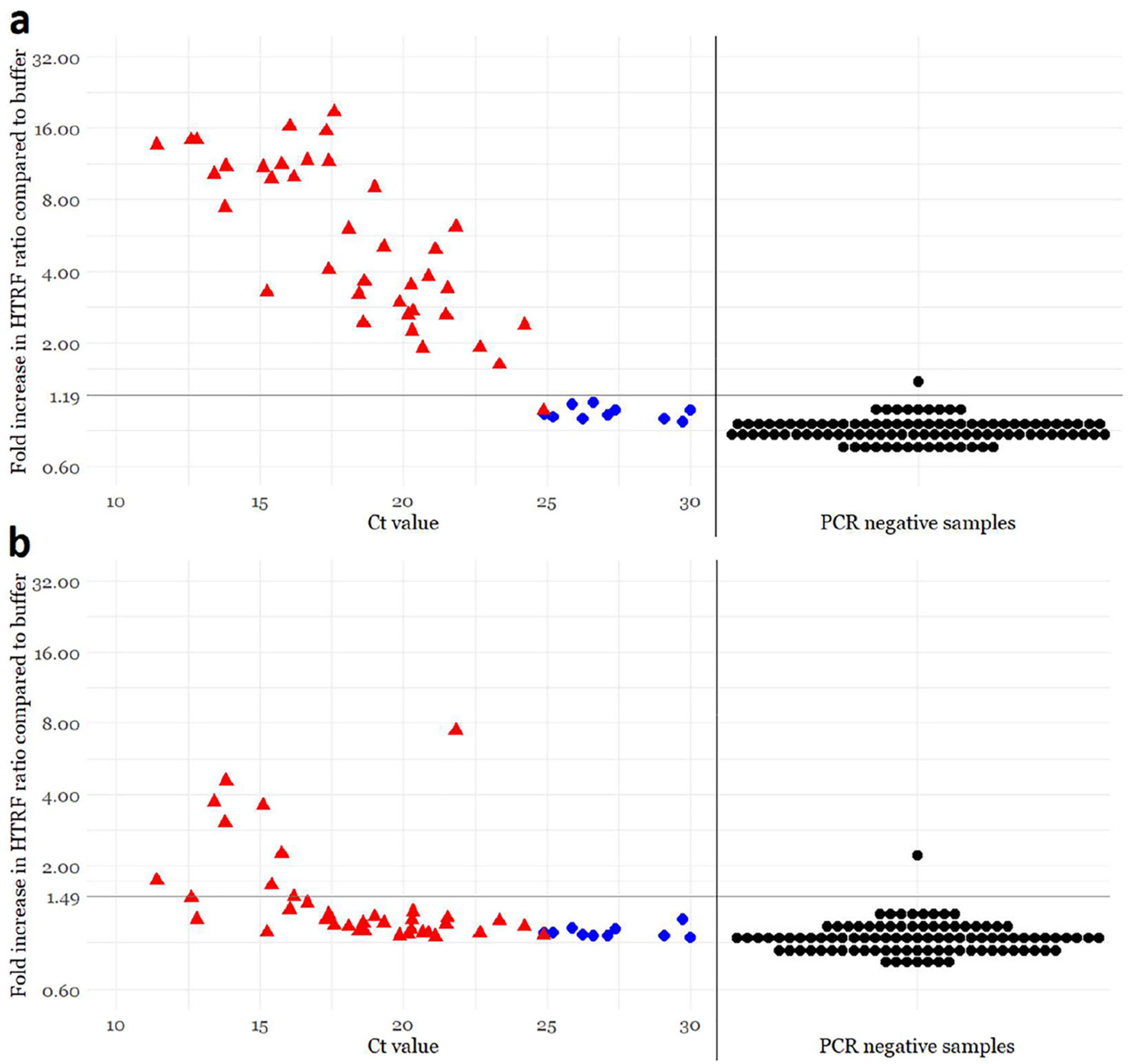

FIG 2 Comparison of time-resolved Förster resonance energy transfer (TR-FRET)-based antigen detection and the amount of virus as analyzed by SARSCoV-2 RT-PCR and virus isolation from NPS samples. The total antibody concentration in the assay mixtures is $12 \mathrm{nM}$ (6 nM Eu- and $6 \mathrm{nM}$ AF647-labeled antibodies). (a) Anti-NP (nucleoprotein) assay results. (b) Anti-RBD (receptor-binding domain) assay results. The $y$ axis (log scale) indicates the fold increase in the homogeneous time-resolved fluorescence (HTRF) ratio $\left(\mathrm{HTRF}_{\text {sample }} / \mathrm{HTRF}_{\text {buffer }}\right)$ measured directly after pipetting the samples onto the plate. The $x$ axis shows the $C_{T}$ values measured in the diagnostic SARS-CoV-2 RT-PCR. The horizontal black line is the antigen test positivity cutoff, corresponding to the average plus 4 standard deviations of the signals induced by SARS-CoV-2 RT-PCR-negative samples. The vertical black line separates SARS-CoV-2 RT-PCRpositive $(n=48)$ and -negative $(n=96)$ NPS samples. The coloring in the graphs indicates the presence (red) or absence (blue) of cytopathic effect (CPE) following inoculation of VE6-TMPRSS2-H10 cells with $50 \mu$ l of the NPS sample. Black, not cultured.

False positivity and cross-reactivity. After finding a total antibody concentration of $12 \mathrm{nM}$ ideal for the assay performance, we were interested in knowing the rate of false-positive results. To that end, we tested 96 SARS-CoV-2 RT-PCR-negative NPS samples in the TR-FRET antigen assays. In parallel, we studied the potential cross-reactivity of the cell culture-grown seasonal common cold coronaviruses hCoV-229E (human coronavirus 229E) and hCoV-NL63 in the TR-FRET assays. Among the SARS-CoV-2 RT-PCRnegative NPS samples, only one produced a positive HTRF signal. We reanalyzed this sample with another RT-PCR assay (Xpert Xpress SARS-CoV-2; Cepheid), confirming the 
a

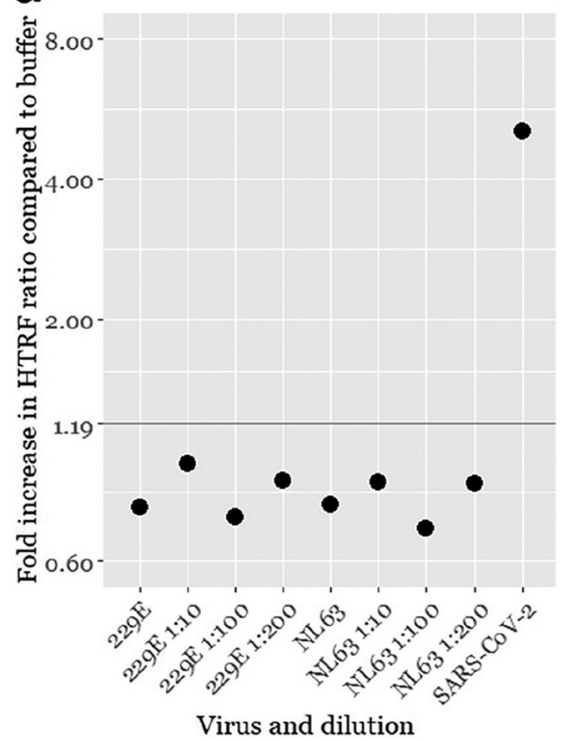

b

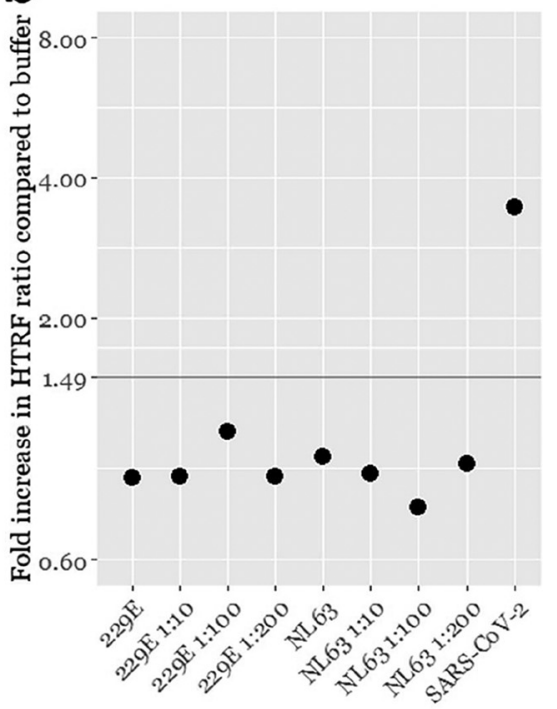

Virus and dilution

FIG 3 SARS-CoV-2 TR-FRET antigen assay cross-reactivity evaluated with cell culture supernatants of seasonal human coronaviruses hCoV-229E and -NL63. (a) Anti-NP assay results with hCoV-229E and -NL63 cell culture supernatants at different dilutions. (b) Anti-NP assay results with hCoV-229E and -NL63 cell culture supernatants at different dilutions. The $y$ axis (log scale) indicates the fold increase in the HTRF ratio $\left(\mathrm{HTRF}_{\text {sample }} / \mathrm{HTRF}_{\text {buffer }}\right)$. The horizontal lines indicate the respective TR-FRET assay cutoffs. A UV-inactivated SARS-CoV-2-containing cell culture supernatant is included as a positive control.

negative result. To assess the antigen specificity of the signal, we also analyzed this sample using mismatching combinations of the labeled anti-NP and anti-RBD antibodies. All of the combinations yielded a positive result, suggesting that something other than the antigens brings the labeled antibodies together. By using the optimized conditions with $12 \mathrm{nM}$ total labeled antibodies, the specificities of NP and SP TR-FRET assays in comparison with RT-PCR were 99.0\% (95/96), and those in comparison with virus isolation were $100 \%$ (10/10). We then set as cutoffs for the TR-FRET assays the average plus 4 standard deviations of the signals from the SARS-CoV-2 RT-PCR-negative NPS samples (excluding the single outlier). Using these cutoffs, neither hCoV-229E nor hCoV-NL63 yielded a signal above the respective cutoffs in the NP or SP TR-FRET assay (Fig. 3). We were unable to obtain other hCoVs (OC43 and HKU1) as virus isolates or as NPS samples in a suitable buffer and thus could not evaluate the cross-reactivity further. The results with the cutoff values selected using the negative NPS samples concurred with those by the arbitrary cutoffs utilized as described above and are summarized in Fig. 2.

\section{DISCUSSION}

The SARS-CoV-2 epidemic that began in China in late 2019 quickly evolved into a pandemic in the spring of 2020. After an initial lag in ramping up the testing capacity, RT-PCR quickly became the gold standard of acute SARS-CoV-2 diagnostics. While RT$P C R$ is very sensitive in picking up individuals with acute infection, the downside is that patients recovering from COVID-19 can remain RT-PCR positive over a long period. Antigen testing, on the other hand, is somewhat less sensitive for detecting patients with acute infection; however, there appears to be a better correlation between the presence of antigen and infectious virus in the NPS samples. In this article, we describe a technique for rapid antigen detection and used SARS-CoV-2 as the model pathogen. We evaluated the test by detecting SARS-CoV-2 antigen in NPS samples and compared the test's performance against virus isolation and RT-PCR. The assay is quick and very 
easy to use; furthermore, the assay is rather uncomplicated to set up provided that specific antibodies against the structural proteins of the virus are available. We employed polyclonal instead of monoclonal antibodies in the assay because we think that an assay relying on polyclonal antibodies would perform better in the case of virus variants. We think that the assay can be set up using monoclonal antibodies and likely combinations or pools of monoclonal antibodies. The fluorophores (chelated Eu and Alexa Fluor 647) are readily available, and the results can be read on any microplate reader capable of measuring time-resolved fluorescence. Notably, we set up the assay in detergent-containing RIPA buffer, which contains 1\% NP-40 and $0.1 \%$ SDS, both of which inactivate SARS-CoV-2 $(15,16)$. Thus, collecting the NPS samples directly into this matrix would significantly increase safety for the end user.

We set up the assay for the detection of both NP and SP of SARS-CoV-2 but observed a clear difference between the LODs of the two assays, with NP being detected at an $\sim 35$-times-lower concentration. This is likely explained by the fact that we employed an antibody directed against the RBD, which constitutes only about onesixth of the SP. The fact that the antibody in use recognizes only a single domain could make it sterically impossible for two antibody molecules to bind a single SP molecule, and thus, we speculate that the obtained signal came from SP trimers, i.e., spikes. NP is more abundant in both virions and infected cells (see Fig. S7 in the supplemental material), which additionally contributed to the higher sensitivity of NP detection in cell culture supernatants and NPS samples. Also, the use of polyclonal antibodies theoretically enables the simultaneous binding of several antibody molecules to a single antigen molecule, thus increasing the assay sensitivity.

Performance analysis of the antigen assay using NPS samples from 48 SARS-CoV-2 RT-PCR-positive and 96 negative individuals revealed that the NP assay correctly identified 37 of the positive samples and all but 1 of the negative samples. All 37 true-positive samples had a $C_{T}$ value of $<25$ cycles in the diagnostic RT-PCR. Similar to other studies, we observed a strong association between the sample infectivity and positive antigen test results: of the 38 samples that yielded an isolate, 37 produced a positive result in the NP assay. We used $50 \mu$ l for virus isolation, while the antigen assay takes only $10 \mu \mathrm{l}$, which could explain why one of the samples with infectious virus was not picked up. We intentionally selected NPS samples over a broad range of $C_{T}$ values in SARS-CoV-2 RT-PCR to obtain an estimate of the detection limit compared to RT-PCR. The fact that we analyzed samples that were not collected fresh and had been subjected to at least one freeze-thaw cycle may have negatively affected the assay sensitivity. In any case, our test could detect $97.4 \%$ of the NPS samples with infectious virus.

Because both NP and SP antigen assays gave a positive result for a single SARSCoV-2 RT-PCR-negative sample, we reanalyzed it using a different RT-PCR with a negative result. We also attempted virus isolation from the sample but without success. It is possible that the false-positive result is a result of cross-reactivity to a human coronavirus (hCoV) infection. Of the hCoVs, only hCoV-NL63 and SARS-CoV use the same receptor as SARS-CoV-2, i.e., angiotensin-converting enzyme 2 (ACE2) $(18,19)$. Thus, it would be most logical that the reactivity of this sample would be due to hCoV-NL63 because both SP (based on the RBD) and NP assays gave a positive result. However, we tested the two assays using cell culture-grown hCoV-229E and hCoV-NL63 but with negative results. Unfortunately, we did not have sample material available for evaluating the potential cross-reactivity against hCoV-OC43 and hCoV-HKU1. It appears that the sample yielding a false-positive reaction contained an interfering substance, which caused the immunoglobulins to aggregate, because labeled antibodies against different antigens also yielded a TR-FRET signal. The use of mismatching antibodies could in the future serve to discern true- and false-positive results in the TR-FRET assay.

In conclusion, we describe an antigen detection assay in which the presence of an antigen is "sensed" by the simultaneous binding of two or more fluorophore-labeled antibody molecules to the antigen. We provide a proof of concept for the assay principle utilizing SARS-CoV-2 NP and SP as the model antigens and demonstrate the assay 
functionality utilizing patient samples. The TR-FRET-based antigen test is rapid to perform, and its results correlate well with the presence of infectious virus in clinical samples. The assay is easy to set up if a suitable antibody against SARS-CoV-2 NP and a plate reader enabling TR-FRET measurement are available. The assay sensitivity is likely lower than those of enzyme-based assays; however, the good correlation of the positive results and virus isolation could indicate that the sensitivity reached was high enough because a test with higher sensitivity would likely also pick up samples from which virus cannot be isolated. Although the assay is not as simple and robust to use as, e.g., lateral flow tests, the assay's clear advantage is in its throughput. We estimate that a single plate reader and an experienced technician could manually analyze hundreds of specimens per hour, ideally with a 30-min turnaround time from sample arrival to results. The assay throughput could significantly be upscaled by using automation, and like RT-PCR, sample collection would represent the major limiting factor. NPS sampling directly into a detergent-containing buffer increases the assay's user safety. We envision that the assay could be applied widely in the field, e.g., hospitals, retirement homes, airports, train stations, and schools, to identify people likely to spread the virus.

\section{MATERIALS AND METHODS}

Patient samples and reference results. The evaluation of the SARS-CoV-2 TR-FRET assay was conducted by using nasopharyngeal swab (NPS) specimens collected in saline. The specimens were retrieved from patients with clinically suspected COVID-19, and they were originally sent to the HUS Diagnostic Center, HUSLAB, for SARS-CoV-2 RT-PCR testing. The specimens were subsequently stored at $-20^{\circ} \mathrm{C}$.

The SARS-CoV-2 RT-PCR was based on a laboratory-developed test (LDT). The details and performance of the test in our laboratory setting have been described previously (20). In this method (based on the $\mathrm{N}$ gene [modified from the method in reference 21]), the specimens were inactivated by combining $250 \mu \mathrm{l}$ of MagNA Pure lysis/binding buffer (Roche Diagnostics GmbH, Mannheim, Germany) and $250 \mu \mathrm{l}$ of the specimen. Nucleic acid extraction was done from $450 \mu \mathrm{l}$ of the specimen lysate with the MagNA Pure viral NA SV 2.0 kit (Roche Diagnostics GmbH, Mannheim, Germany). RT-PCR was performed using the SuperScript III Platinum one-step qRT-PCR kit with $600 \mathrm{nM}$ the forward primer CACATTGGCACCCGCAATC, $800 \mathrm{nM}$ the reverse primer GAGGAACGAGAAGAGGCTTG, and $200 \mathrm{nM}$ the probe FAM (6-carboxyfluorescein)-ACTTCCTCAAGGAACAACATTGCCA-BBQ (blackberry quencher).

The SARS-CoV-2 RT-PCR-positive panel comprised 48 specimens with cycle threshold $\left(C_{T}\right)$ values ranging linearly between 11.42 and 29.98 in the LDT. The SARS-CoV-2 RT-PCR-negative panel comprised 96 samples negative in the LDT. Patient data were collected and samples were handled according to a research permit approved by the local review board, permit HUS/32/2018 (Helsinki University Hospital, Finland).

Cell lines, virus isolation, and propagation. Vero E6 cells were transduced with a lentiviral vector expressing human transmembrane serine protease 2 (TMPRSS2) transcript variant 2 cDNA (GenBank accession number NM_005656.4) and blasticidin as a selection marker. Specifically, $1 \mathrm{ml}$ of the $0.22-\mu \mathrm{m}$ filtered (Millipore) infectious supernatant of HEK293T cells transfected on a $10-\mathrm{cm}$ plate $48 \mathrm{~h}$ earlier using $30 \mu \mathrm{g}$ polyethylenimine with $5 \mu \mathrm{g}$ pLenti6.3/V5-DEST TMPRSS2 (obtained from the Biomedicum Functional Genomics Unit, University of Helsinki), $5 \mu \mathrm{g}$ p8.9NDSB (22), and 2 to $5 \mu \mathrm{g}$ pMD2.G (a gift from Didier Trono [Addgene plasmid 12259 \{https://n2t.net/addgene:12259\}; RRID, Addgene_12259]) was added to Vero E6 cells seeded onto 6-well plates. Following 2 days of selection with $15 \mu \mathrm{g} / \mathrm{ml}$ of blasticidin $\mathrm{S} \mathrm{HCl}$ (Invitrogen), the cells were allowed to expand until confluence and subcultured three times. Once confirmed p24 negative, a clonal population of Vero E6-TMPRSS2 cells was obtained by limiting dilution. The obtained clones $(n=5)$ were analyzed for TMPRSS2 expression by immunoblotting with V5 antibody (Invitrogen). The clone expressing the largest amount of TMPRSS2, VE6-TMPRSS2-H10, was selected for use.

SARS-CoV-2 isolation from clinical samples (stored at $-20^{\circ} \mathrm{C}$ since the day of collection and not subjected to freeze-thawing) was attempted on both Vero E6 and VE6-TMPRSS2-H10 cells. Both cell lines were cultivated in Eagle minimal essential medium (MEM; Sigma) supplemented with $10 \%$ fetal bovine serum (FBS; Gibco), $100 \mathrm{IU}$ penicillin plus $100 \mu \mathrm{g} / \mathrm{ml}$ streptomycin (Sigma), and $2 \mathrm{mM}$ L-glutamine (Sigma). For isolation, the cells were grown on 12-well plates until approximately $90 \%$ confluent, and the growth medium was replaced with $400 \mu \mathrm{l}$ of MEM-2\% (MEM as described above but with $2 \% \mathrm{FBS}$ ), followed by the addition of $50 \mu$ l of the NPS sample (under biosafety level 3 [BSL-3] conditions) and $1 \mathrm{~h}$ of incubation at $37^{\circ} \mathrm{C}$ with $5 \% \mathrm{CO}_{2}$. After two washes with $\mathrm{MEM}-2 \%$, cultures were kept in $1 \mathrm{ml}$ fresh MEM- $2 \%$ for 4 days at $37^{\circ} \mathrm{C}\left(5 \% \mathrm{CO}_{2}\right)$, the medium was collected and clarified by centrifugation $(3,000$ relative centrifugal force [rcf] for $5 \mathrm{~min}$ ), and the cells were fixed for $15 \mathrm{~min}$ at room temperature with 3.7\% formaldehyde in phosphate-buffered saline (PBS) followed by a PBS wash and UV inactivation $\left(500,000 \mu \mathrm{J} / \mathrm{cm}^{2}\right.$, UV Crosslinker CL-1000; Jena Analytik). The fixed cells were crystal violet stained, and the extent of cytopathic effect (CPE) was scored from 0 to 3 (from nonobservable to extensive cell death). To confirm infection, RNA was extracted (Qiagen QIAamp viral RNA extraction kit, according to 
the manufacturer's protocol) from $100 \mu \mathrm{l}$ of each cell culture supernatant, and the presence or absence of SARS-CoV-2 was analyzed by RT-PCR targeting the RdRp (RNA-dependent RNA polymerase) gene as described previously (21).

For TR-FRET antigen detection experiments, we produced a stock of SARS-CoV-2 in Vero E6 cells (23). Briefly, 90 to $95 \%$ confluent Vero E6 cells were inoculated with $500 \mu$ l of the 1:100-diluted SARS-CoV-2containing supernatant (passage 7, approximately $5 \times 10^{7} 50 \%$ tissue culture infectious doses $\left[\right.$ TCID $\left._{50}\right]$ per $\mathrm{ml}$ ). After $1 \mathrm{~h}$ of virus adsorption, the medium was replaced with $\mathrm{MEM}-2 \%$, and after 2 days at $37^{\circ} \mathrm{C}$ with $5 \% \mathrm{CO}_{2}$, the supernatant was collected, clarified by centrifugation (3,000 rcf for $5 \mathrm{~min}$ ), and stored in aliquots at $-80^{\circ} \mathrm{C}$. UV inactivation of the culture supernatants was done as described above.

Human coronaviruses 229E (hCoV-229E) (kindly provided by Sisko Tauriainen, University of Turku, Turku, Finland) and NL63 (hCoV-NL63) (kindly provided by Lia van der Hoek, Academic Medical Center, Amsterdam, Netherlands) served as controls for estimating the cross-reactivity of the assay. The hCoV$229 E$ stock was produced by inoculating LLC-MK2 rhesus macaque kidney cells (from the ATCC) with $500 \mu \mathrm{l}$ of the $1: 1,000$-diluted cell culture supernatant (approximately $5 \times 10^{9} \mathrm{TCID}_{50} / \mathrm{ml}$ ) for $1 \mathrm{~h}$ at $37^{\circ} \mathrm{C}$ with $5 \% \mathrm{CO}_{2}$. After virus adsorption, the medium was changed into MEM-2\%, the cells were grown for 5 days $\left(37^{\circ} \mathrm{C}\right.$ with $\left.5 \% \mathrm{CO}_{2}\right)$, and the supernatant was collected, centrifuged (3,000 rcf for $\left.5 \mathrm{~min}\right)$, and stored in aliquots at $-80^{\circ} \mathrm{C}$. The hCoV-NL63 stock was produced by inoculating human lung fibroblasts (MRC-5; ATCC) with $500 \mu \mathrm{l}$ of 1:100-diluted cell culture supernatants (approximately $1 \times 10^{6} \mathrm{TCID}_{50} / \mathrm{ml}$ ) for $1 \mathrm{~h}$ at $37^{\circ} \mathrm{C}$ with $5 \% \mathrm{CO}_{2}$. After virus adsorption, the media were replaced with $\mathrm{MEM}-2 \%$, the cells were grown for 7 days (until the appearance of definitive CPE), and the supernatants were collected, centrifuged $(3,000 \mathrm{rcf}$ for $5 \mathrm{~min})$, and stored in aliquots at $-80^{\circ} \mathrm{C}$. The hCoV-229E and hCoV-NL63 supernatants were inactivated for the experiments by mixing at a 1:10 dilution in RIPA buffer $(50 \mathrm{mM}$ Tris- $\mathrm{HCl}$ [pH 8.0], $150 \mathrm{mM} \mathrm{NaCl}, 1 \% \mathrm{NP}-40,0.1 \%$ SDS, 0.5\% sodium deoxycholate, and Roche cOmplete EDTA-free protease inhibitor cocktail).

Antigens and antibodies. The production and purification of SARS-CoV-2 NP and SP antigens were performed according to previously described protocols $(14,24,25)$. The RBD of the SP was produced in Expi293F cells as previously described $(24,25)$. Rabbit antisera against the RBD and NP were generated at BioGenes GmbH (Berlin, Germany) as follows: day 0 initial dose of $150 \mu \mathrm{g}$, day 7 booster of $75 \mu \mathrm{g}$, day 14 booster of $75 \mu \mathrm{g}$, day 28 booster of $150 \mu \mathrm{g}$, and day 42 final bleed. For affinity purification, the RBD and NP were coupled to CNBr-Sepharose 4B (Cytiva) according to the manufacturer's protocol. The respective antisera were passed through coupled Sepharoses packed into Poly-Prep chromatography columns (Bio-Rad), washed with 20 column volumes of PBS, eluted (0.1 M glycine, $150 \mathrm{mM} \mathrm{NaCl}[\mathrm{pH} 2.5]$ ) with $2 \mathrm{M}$ Tris ( $\mathrm{pH}$ 9.0), concentrated using an Amicon Ultra 15-ml 100-kDa-NMWL (nominal molecular weight limit) centrifugal filter (Millipore/Merck), and dialyzed against PBS using Slide-A-Lyzer dialysis cassettes (Thermo Scientific).

Labeling. We labeled the affinity-purified antibodies, at $250 \mu \mathrm{g} / \mathrm{reaction}$, with the donor (europium [Eu]) and acceptor (Alexa Fluor 647 [AF647]) using a QuickAllAssay Eu-chelated protein labeling kit (BN Products and Services Oy) and Alexa Fluor 647 NHS (N-hydroxysuccinimide) ester (Thermo Scientific) according to the manufacturer's instructions. A disposable PD-10 desalting column with Sephadex G-25 resin (Cytiva) served to remove nonreacted fluorophores, and an Amicon Ultra 0.5-ml 50-kDa-NMWL centrifugal filter (Millipore/Merck) was used for concentrating the labeled antibodies, which were then stored aliquoted at $-80^{\circ} \mathrm{C}$ until use.

TR-FRET assays. First, we set up TR-FRET assays for SARS-CoV-2 SP and NP antigens by using the respective purified proteins as well as the corresponding Eu- and AF-labeled anti-RBD and anti-NP antibodies. The assay principle and workflow are depicted in Fig. 1. Briefly, antibody mixes with equimolar concentrations of Eu- and AF-labeled anti-RBD and anti-NP antibody concentrations were prepared in RIPA buffer. For setting up the assay, a pool of four SARS-CoV-2-negative NPS samples was divided into aliquots and spiked with either NP or SP proteins at various concentrations. Ten microliters of the antibody mix was pipetted on a 384-well microplate (ProxiPlate 384 Plus F, black 384-shallow-well microplate; PerkinElmer, USA), followed by $10 \mu$ l of the antigen-spiked sample. The TR-FRET signal was measured directly thereafter and $7,15,22,30,45,60$, and 90 min after the first measurement with a Hidex Sense microplate reader (Hidex Oy, Finland). FRET donor excitation was done at $330 \mathrm{~nm}$, and after a delay of $70 \mu \mathrm{s}$, the donor and acceptor signals were measured for $100 \mu \mathrm{s}$ at 616 and $665 \mathrm{~nm}$, respectively. TR-FRET signals were expressed as HTRF ratios, calculated as follows: HTRF ratio $=$ emission at $616 \mathrm{~nm} / \mathrm{emission}$ at $665 \mathrm{~nm} \times$ 10,000. Thereafter, the HTRF ratios measured from the antigen-spiked samples were compared with those measured from a nonspiked sample in the same run to calculate the fold increase in the HTRF ratio. Antibody plate concentrations ranging from 5 to $500 \mathrm{nM}$ (one-half Eu and one-half AF labeled) were crosstitrated with antigen plate concentrations ranging from $5 \mathrm{nM}$ to $500 \mathrm{nM}$.

The ranges of antigen concentrations detectable by TR-FRET (at Eu- and AF-labeled anti-NP/RBD concentrations of 6 and $6 \mathrm{nM}$ ) were then assessed by performing the assay as described above using $\mathrm{N}$ and S plate concentrations of $5 \mathrm{fM}$ to $5 \mathrm{nM}$.

To assess the assay performance with samples containing virions, cell culture supernatants containing roughly $10^{7} \mathrm{TCID}_{50} / \mathrm{ml}$ of SARS-CoV-2 were used. For initial experiments (carried out in a BSL-3 laboratory), an infectious cell culture supernatant (undiluted and 1:10, 1:25, 1:50, and 1:100 diluted in RIPA buffer) was used. After verifying that UV-inactivated virus produced similar results, the negative NPS sample matrix was spiked with a UV-inactivated virus-containing cell culture supernatant to yield a dilution series from 1:10 to $1: 20,480$. The samples were tested in the TR-FRET assays performed as described above at Eu- and AF-labeled anti-NP/RBD concentrations of 6 and $6 \mathrm{nM}$.

NPS sample analysis was done by mixing $10 \mu \mathrm{l}$ of the sample with $10 \mu \mathrm{l}$ of the antibody mixes (Euand AF-labeled anti-NP/RBD concentrations of 6 and $6 \mathrm{nM}$ ). The TR-FRET assays with SARS-CoV-2 RT- 
PCR-positive NPS samples were carried out in a BSL-3 laboratory, and those with RT-PCR-negative samples were carried out in a BSL-2 laboratory. The signals produced by hCoV-229E and hCoV-NL63 were evaluated by mixing $10 \mu \mathrm{l}$ (undiluted and 1:10, 1:25, 1:50, and 1:100 diluted in RIPA buffer) of the cell culture supernatant with $10 \mu \mathrm{l}$ of the antibody mixes (at Eu- and AF-labeled anti-NP/RBD concentrations of 6 and $6 \mathrm{nM})$

\section{SUPPLEMENTAL MATERIAL}

Supplemental material is available online only.

FIG S1, PDF file, $0.2 \mathrm{MB}$

FIG S2, PDF file, $0.2 \mathrm{MB}$.

FIG S3, PDF file, $0.2 \mathrm{MB}$.

FIG S4, PDF file, $0.2 \mathrm{MB}$.

FIG S5, PDF file, $0.1 \mathrm{MB}$.

FIG S6, PDF file, $0.3 \mathrm{MB}$.

FIG S7, PDF file, $0.4 \mathrm{MB}$.

FIG S8, PDF file, $0.2 \mathrm{MB}$.

FIG S9, PDF file, $0.1 \mathrm{MB}$.

TABLE S1, PDF file, $0.1 \mathrm{MB}$.

\section{ACKNOWLEDGMENTS}

We acknowledge Sisko Tauriainen (University of Turku, Turku, Finland) and Lia van der Hoek (Academic Medical Center, Amsterdam, Netherlands) for providing the human coronaviruses used for evaluating cross-reactivity.

The study was supported by the Academy of Finland (grants 308613, 314119, and 335762 to J.H.).

\section{REFERENCES}

1. Arons MM, Hatfield KM, Reddy SC, Kimball A, James A, Jacobs JR, Taylor J, Spicer K, Bardossy AC, Oakley LP, Tanwar S, Dyal JW, Harney J, Chisty Z, Bell JM, Methner M, Paul P, Carlson CM, McLaughlin HP, Thornburg N, Tong S, Tamin A, Tao Y, Uehara A, Harcourt J, Clark S, Brostrom-Smith C, Page LC, Kay M, Lewis J, Montgomery P, Stone ND, Clark TA, Honein MA, Duchin JS, Jernigan JA. 2020. Presymptomatic SARS-CoV-2 infections and transmission in a skilled nursing facility. N Engl J Med 382:2081-2090. https://doi.org/10.1056/NEJMoa2008457.

2. Bullard J, Dust K, Funk D, Strong JE, Alexander D, Garnett L, Boodman C, Bello A, Hedley A, Schiffman Z, Doan K, Bastien N, Li Y, Van Caeseele PG, Poliquin G. 2020. Predicting infectious severe acute respiratory syndrome coronavirus 2 from diagnostic samples. Clin Infect Dis 71:2663-2666. https://doi.org/10.1093/cid/ciaa638.

3. Wölfel R, Corman VM, Guggemos W, Seilmaier M, Zange S, Müller MA, Niemeyer $D$, Jones TC, Vollmar $P$, Rothe $C$, Hoelscher $M$, Bleicker $T$, Brünink S, Schneider J, Ehmann R, Zwirglmaier K, Drosten C, Wendtner C. 2020. Virological assessment of hospitalized patients with COVID-2019. Nature 581:465-469. https://doi.org/10.1038/s41586-020-2196-x.

4. Pekosz A, Cooper CK, Parvu V, Li M, Andrews JC, Manabe YC, Kodsi S, Leitch J, Gary DS, Roger-Dalbert C. 2020. Antigen-based testing but not real-time PCR correlates with SARS-CoV-2 virus culture. medRxiv https:// doi.org/10.1101/2020.10.02.20205708.

5. Mina MJ, Parker R, Larremore DB. 2020. Rethinking Covid-19 test sensitivity-a strategy for containment. N Engl J Med 383:e120. https://doi.org/ 10.1056/NEJMp2025631.

6. Dinnes J, Deeks JJ, Adriano A, Berhane S, Davenport C, Dittrich S, Emperador D, Takwoingi Y, Cunningham J, Beese S, Dretzke J, Ferrante di Ruffano L, Harris IM, Price MJ, Taylor-Phillips S, Hooft L, Leeflang MMG, Spijker R, Van den Bruel A, Cochrane COVID-19 Diagnostic Test Accuracy Group. 2020. Rapid, point-of-care antigen and molecular-based tests for diagnosis of SARS-CoV-2 infection. Cochrane Database Syst Rev 8: CD013705. https://doi.org/10.1002/14651858.CD013705.

7. US Food and Drug Administration. 2020. Coronavirus disease 2019 (COVID-19) emergency use authorizations for medical devices: in vitro diagnostic EUAs. US Food and Drug Administration, Silver Spring, MD. https://www.fda.gov/medical-devices/coronavirus-disease-2019-covid-19 -emergency-use-authorizations-medical-devices/vitro-diagnostics-euas.
8. Saraheimo S, Hepojoki J, Nurmi V, Lahtinen A, Hemmila I, Vaheri A, Vapalahti O, Hedman K. 2013. Time-resolved FRET-based approach for antibody detection-a new serodiagnostic concept. PLoS One 8:e62739. https://doi.org/10.1371/journal.pone.0062739.

9. Hepojoki S, Nurmi V, Vaheri A, Hedman K, Vapalahti O, Hepojoki J. 2014. A protein L-based immunodiagnostic approach utilizing time-resolved Forster resonance energy transfer. PLoS One 9:e106432. https://doi.org/10 .1371/journal.pone.0106432.

10. Hepojoki S, Hepojoki J, Hedman K, Vapalahti O, Vaheri A. 2015. Rapid homogeneous immunoassay based on time-resolved Förster resonance energy transfer for serodiagnosis of acute hantavirus infection. J Clin Microbiol 53:636-640. https://doi.org/10.1128/JCM.02994-14.

11. Hepojoki S, Rusanen J, Hepojoki J, Nurmi V, Vaheri A, Lundkvist A, Hedman K, Vapalahti O. 2015. Competitive homogeneous immunoassay for rapid serodiagnosis of hantavirus disease. J Clin Microbiol 53:2292-2297. https:// doi.org/10.1128/JCM.00663-15.

12. Kareinen L, Hepojoki S, Huhtamo E, Korhonen EM, Schmidt-Chanasit J, Hedman K, Hepojoki J, Vapalahti O. 2019. Immunoassay for serodiagnosis of Zika virus infection based on time-resolved Forster resonance energy transfer. PLoS One 14:e0219474. https://doi.org/10.1371/journal pone.0219474.

13. Rusanen J, Toivonen A, Hepojoki J, Hepojoki S, Arikoski P, Heikkinen $M$, Vaarala O, llonen J, Hedman K. 2019. LFRET, a novel rapid assay for antitissue transglutaminase antibody detection. PLoS One 14:e0225851. https://doi.org/10.1371/journal.pone.0225851.

14. Rusanen J, Kareinen L, Levanov L, Mero S, Pakkanen SH, Kantele $A$, Amanat F, Krammer F, Hedman K, Vapalahti O, Hepojoki J. 2021. A 10-minute "mix and read" antibody assay for SARS-CoV-2. Viruses 13:143. https://doi.org/10.3390/v13020143.

15. Welch SR, Davies KA, Buczkowski $H$, Hettiarachchi N, Green $N$, Arnold $U$, Jones M, Hannah MJ, Evans R, Burton C, Burton JE, Guiver M, Cane PA, Woodford N, Bruce CB, Roberts ADG, Killip MJ. 2020. Analysis of inactivation of SARS-CoV-2 by specimen transport media, nucleic acid extraction reagents, detergents, and fixatives. J Clin Microbiol 58:e01713-20. https:// doi.org/10.1128/JCM.01713-20

16. Patterson El, Prince T, Anderson ER, Casas-Sanchez A, Smith SL, CansadoUtrilla C, Solomon T, Griffiths MJ, Acosta-Serrano Á, Turtle L, Hughes GL. 
2020. Methods of inactivation of SARS-CoV-2 for downstream biological assays. J Infect Dis 222:1462-1467. https://doi.org/10.1093/infdis/jiaa507.

17. Hoffmann M, Kleine-Weber $H$, Schroeder S, Krüger N, Herrler T, Erichsen $S$ Schiergens TS, Herrler G, Wu N, Nitsche A, Müller MA, Drosten C, Pöhlmann S. 2020. SARS-CoV-2 cell entry depends on ACE2 and TMPRSS2 and is blocked by a clinically proven protease inhibitor. Cell 181:271-280. e8. https://doi.org/10.1016/j.cell.2020.02.052.

18. Hofmann H, Pyrc K, van der Hoek L, Geier M, Berkhout B, Pöhlmann S. 2005. Human coronavirus NL63 employs the severe acute respiratory syndrome coronavirus receptor for cellular entry. Proc Natl Acad Sci U S A 102:7988-7993. https://doi.org/10.1073/pnas.0409465102.

19. Li F. 2015. Receptor recognition mechanisms of coronaviruses: a decade of structural studies. J Virol 89:1954-1964. https://doi.org/10.1128/JVI .02615-14.

20. Mannonen L, Kallio-Kokko $H$, Loginov $R$, Jääskeläinen $A$, Jokela $P$, Antikainen J, Väre P, Kekäläinen E, Kurkela S, Jarva H, Lappalainen M. 2021. Comparison of two commercial platforms and a laboratory developed test for detection of SARS-CoV-2 RNA. J Mol Diagn 23:407-416. https://doi.org/10.1016/j .jmoldx.2021.01.005.

21. Corman VM, Landt O, Kaiser M, Molenkamp R, Meijer A, Chu DKW, Bleicker T, Brünink S, Schneider J, Schmidt ML, Mulders DGJC, Haagmans $B L$, van der Veer B, van den Brink S, Wijsman L, Goderski G, Romette J-L, Ellis J, Zambon M, Peiris M, Goossens H, Reusken C, Koopmans MPG, Drosten C. 2020. Detection of 2019 novel coronavirus (2019-nCoV) by real-time RT-PCR. Euro Surveill 25:2000045. https://doi.org/10.2807/1560 -7917.ES.2020.25.3.2000045.
22. Berthoux L, Sebastian S, Sokolskaja E, Luban J. 2004. Lv1 inhibition of human immunodeficiency virus type 1 is counteracted by factors that stimulate synthesis or nuclear translocation of viral cDNA. J Virol 78:11739-11750. https://doi.org/10.1128/JVI.78.21.11739-11750.2004.

23. Haveri A, Smura T, Kuivanen S, Osterlund P, Hepojoki J, Ikonen N, Pitkapaasi M, Blomqvist S, Ronkko E, Kantele A, Strandin T, Kallio-Kokko H, Mannonen L, Lappalainen M, Broas M, Jiang M, Siira L, Salminen M, Puumalainen T, Sane J, Melin M, Vapalahti O, Savolainen-Kopra C. 2020. Serological and molecular findings during SARS-CoV-2 infection: the first case study in Finland, January to February 2020. Euro Surveill 25:2000266. https://doi.org/10.2807/1560-7917.ES.2020.25.11.2000266.

24. Stadlbauer D, Amanat F, Chromikova V, Jiang K, Strohmeier S, Arunkumar GA, Tan J, Bhavsar D, Capuano C, Kirkpatrick E, Meade P, Brito RN, Teo C, McMahon M, Simon V, Krammer F. 2020. SARS-CoV-2 seroconversion in humans: a detailed protocol for a serological assay, antigen production, and test setup. Curr Protoc Microbiol 57:e100. https://doi.org/10.1002/ cpmc. 100.

25. Amanat F, Stadlbauer D, Strohmeier S, Nguyen THO, Chromikova V, McMahon M, Jiang K, Arunkumar GA, Jurczyszak D, Polanco J, BermudezGonzalez M, Kleiner G, Aydillo T, Miorin L, Fierer DS, Lugo LA, Kojic EM, Stoever J, Liu STH, Cunningham-Rundles C, Felgner PL, Moran T, GarcíaSastre A, Caplivski D, Cheng AC, Kedzierska K, Vapalahti O, Hepojoki JM, Simon V, Krammer F. 2020. A serological assay to detect SARS-CoV-2 seroconversion in humans. Nat Med 26:1033-1036. https://doi.org/10.1038/ s41591-020-0913-5. 